\title{
The Study on the Effect of Waiting Time for Medical Treatment and Medical Convenience on Patient Perceived Value
}

\author{
Based on an Empirical Research in China
}

\author{
Hui Qian \\ Department of Business \\ Zhejiang University City College \\ Hangzhou, China \\ qianh@zucc.edu.cn
}

\author{
Yiwei $\mathrm{Wu}^{*}$ \\ Department of Business \\ Zhejiang University City College \\ Hangzhou, China \\ wuyw@zucc.edu.cn \\ *Corresponding author
}

\begin{abstract}
In China, the long waiting time and inconvenience in taking medical treatment are common problems that patients complaint about usually. A number of hospitals have allocated a lot of money for solving the problems and improving the medical service. Although plenty of resources are allocated into it, the problems have not been solved yet. Based on the theory of patient perceived value and combined with the empirical study with cases of large and well-known hospitals in Zhejiang Province of China, the study did a research in the impact of the waiting time and convenience on patient perceived value. According to the research findings, there is no correlation between patients' personal time adequacy and perceived convenience, but there is a positive correlation between perceived convenience and perceived value. The characteristics of patients have a certain influence on adequate time extent and perceived convenience.
\end{abstract}

Keywords-Patient Perceived Value; Patients' Satisfaction in China; Hospital Management

\section{INTRODUCTION}

Having difficulty in receiving medical care is currently one of the issues in the area of the public health in China. The main reason is the decreasing patient perceived value that caused by the long waiting time, the inconvenience to receive medical service and other related problems. Focusing on the relationships between patient waiting time for medical treatment, amenity of taking medical care and patient perceived value, this paper did a theoretical and empirical research on the hot issue in order to provide realistic basis for reducing difficulty on receiving medical care and improving medical service quality through summarizing the rules of the relationships and exploring the methods to improve medical service.

\section{RESEARCH DESIGN}

\section{A. The Theory of Service Convenience}

In the consumer theory, convenience refers to the customers' perceptions of the time and effort related to purchasing and consuming goods and services [1]. Time and effort are the non-monetary cost to customers. Also customers always tend to spend less time and effort in purchasing goods and service. If customers spend more time and efforts than they planed to when buying a product or service, they would feel inconvenient. On the contrary, they would feel convenient. In many cases, inconvenience is found out as the determinant of customers' decision to switch services [2].

Berry (2002) has built the Service Convenience Model and proposed five types of service convenience, which are decision convenience, access convenience, transaction convenience, benefit convenience, and post-sale convenience. A customer's perception of service convenience is based on a comprehensive evaluation on the customer's feelings of the five convenience types, combining with companies' influence and other factors [1].

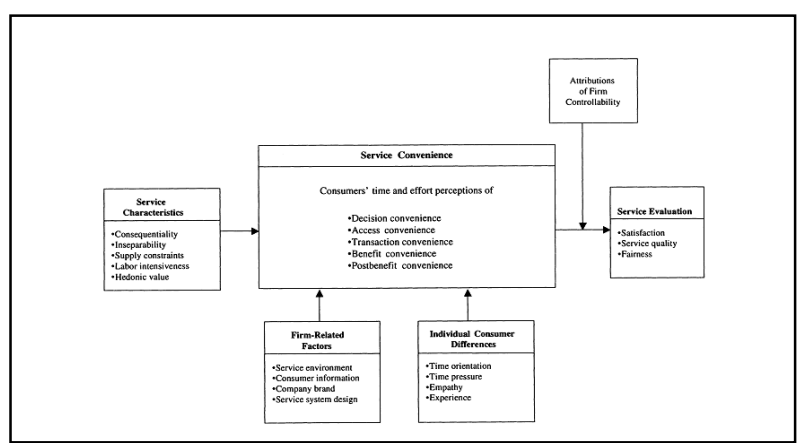

FIGURE I. A MODEL OF SERVICE CONVENIENCE

\section{B. Waiting Time}

Time is an important dimension of service convenience and it could be defined from two aspects: objective and subjective. Objective time, with the feature of continuity and uniformity, can be measured numerically. While subjective time that is based on individual's perceptions of time and experience of waiting can be affected by psychological factors. Customers will feel stressed, bored, anxious and worried during a long waiting for services, and the series of 
mood would usually affect the customers' evaluation and satisfaction of the service [3]. The main factors that mostly influence the customers' perceptions of waiting time are service quality, facilities, customers' characteristics, fairness in the waiting process, and the information of waiting situation.

\section{Theory of Perceived Value}

Customer Perceived Value is an overall assessment through weighing up the utility gained from a product (or service) and the cost paid on it [7]. Applied the theory into the medical care, the patient perceived value of medical treatment is also an overall assessment of medical skill and service quality which is based on weighing up the utility gained from good effects, service and environment during medical treatments and the cost paid like time, money, and treatment risk. Only if the medical organizations provide high quality service to the patients continuously, can the patients' satisfaction and loyalty be obtained sustainably[5].

\section{Hypotheses}

Perceived convenience is one dimension of the patient perceived value and it would be affected by various patients' characteristics and time pressure (the time adequacy of receiving medical treatment). Figure 2 shows the research model of the paper and four assumptions are proposed as follows.

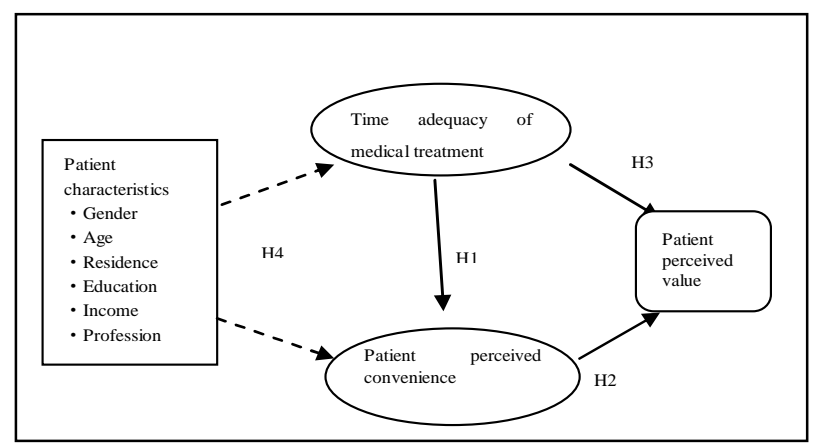

FIGURE II. HYPOTHESIZED MODEL

H1: Time adequacy of medical treatment has a positive correlation with patient perceived convenience.

$\mathrm{H} 2$ : Patient perceived convenience has a positive correlation with patient perceived value.

H3: Time adequacy of medical treatment has a positive correlation with patient perceived value.

H4: Both time adequacy of medical treatment and patient perceived convenience are affected by patient characteristics.

\section{E. Scale design of the empirical study}

According to the above hypotheses, combing the methods like literature review and interviews, we have designed the questionnaire and conducted the relevant test. The final patient perceived value questionnaire consists of three parts: basic information about customers, the key indicators of medical service quality and the experience of taking medical treatment. Among the previous three parts, the assessment of medical treatment experience consists of six dimensions including treatment effect, medical convenience, effective communication, comfort, price, and hospital reputation as well as the general evaluation of the experience. The basic information includes gender, age, education, residence, profession, time adequacy of medical treatment. Considering the medical convenience, two dimensions of it have been set: the reasonable degree of waiting time and the convenience in the process of receiving medical care service.

This study has been conducted through two surveys. The first one was carried out in Taizhou Hospital including its three branches in Linhai, Luqiao, and Jiaojiang. In this survey, 340 questionnaires have been sent out and 263 of them have been received. The second one was taken in other 7 hospitals in Zhejiang province, including Taizhou First People's Hospital, Dongyang People's Hospital, Yiwu Central Hospital, Hangzhou First People's Hospital, First and Second Affiliated Hospital Zhejiang University College of Medicine, and Ningbo Beilun People's Hospital. In this survey, 2100 questionnaires have been sent out and 1944 of them have been received. In all the 2207 valid questionnaires, about $55 \%$ of them were received from inpatients, and the rest $45 \%$ of them were collected from outpatients. Among the 2207 participators, $47 \%$ of them are male and the others are female patients.

According to the analysis of the data collected from the questionnaires, some findings have been concluded in the next part.

\section{THE ANALYSIS OF THE RESULT}

\section{A. The relationship between time adequacy of medical treatment and patient perceived value}

The results show that neither the patients' overall assessment of hospital nor the medical treatment effect is relevant to the time adequacy of medical care. Grouping the sample by the time adequacy, it shows that the patients' overall assessment of hospital and the perception of treatment effect of different groups have no difference from one to other. $(\mathrm{P}>0.05)$.

\section{B. The relationship between waiting time, convenience, patient perceived value, and the degrees of time adequacy}

The related analysis indicates that the two factors, reasonable degrees of waiting time and convenience, have positive correlations with patient perceived value and overall assessment respectively $(\mathrm{P}<0.01)$. However, it shows no relevance between the adequacy of time and the two factors $(\mathrm{P}>0.05)$.

\section{The various feelings of time adequacy, convenience and perceived value from patients with different characteristics}

There is no difference in time adequacy between inpatients and outpatients. By grouping the patients by gender, residence and income, the difference of time adequacy hardly convey any statistically significance. Nevertheless, if the patients were grouped by age, there is significant difference between groups $(\mathrm{F}=2.287, \mathrm{P}<0.05)$ and the group of " 60 -year-old and older" has more spare 
time than others. According to the groups of different education levels, a difference $(\mathrm{F}=2.771, \mathrm{P}<0.05)$ emerges in time adequacy. The groups of higher school and technical secondary school have more time pressure than other groups. Grouped by profession, the difference is also significant $(\mathrm{F}=2.285, \mathrm{P}<0.05)$. When technicians, businessmen selfemployed person, farmers have tight schedules, public servants have much spare time.

There are significant discrepancies of the perception of waiting time, convenience between inpatients and outpatients $(\mathrm{F}=18.461, \mathrm{P}<0.01 ; \mathrm{F}=11.331, \mathrm{P}<0.01)$. Inpatients mark higher grades to convenience of treatment than outpatients. The male and female patients' perceptions of waiting time differ from each other $(\mathrm{F}=5.060, \mathrm{P}<0.05)$ while their perceptions of convenience show no difference. Groups of age have different opinions on waiting time and convenience $(\mathrm{F}=2.297, \mathrm{P}<0.05 ; \mathrm{F}=3.828, \mathrm{P}<0.01)$, and the older age group has better perception of convenience. The perceptions of waiting time differ from people living in different areas $(\mathrm{F}=3.697, \mathrm{P}<0.05)$. People from rural areas give higher score to reasonable waiting time, but all the groups show similar thought in terms of convenience. People with different education levels have different views about waiting time $(\mathrm{F}=4.547, \mathrm{P}<0.01)$. The group of junior college and higher degree marks a lower level on the rationality of waiting time while all groups reached a consensus on convenience of medical care. People with different income share same perceptions of waiting time whereas they think differently about convince $(\mathrm{F}=5.528, \mathrm{P}<0.01)$. Specifically, two groups (group $¥ 400-499$ and group $¥ 3000-4000$ ) have lower perception of convenience. Different vocations display no significant difference in the perception of waiting time and convenience.

Different characteristics of patients do not display any difference in treatment effect. As for the overall assessment of hospitals, inpatients have better feedback than outpatients $(\mathrm{F}=6.319, \mathrm{P}<0.05)$ and male patients hold better perception than females $(\mathrm{F}=4.194, \mathrm{P}<0.05)$. In addition, age, residence, education level, income, profession have no significant impact on overall assessment.

\section{DISCUSSION}

The findings of the empirical research reflect that there is no relevance between time adequacy of medical treatment and patient perceived convenience, so the hypothesis 1 is false. Hypothesis 2 has been proved correct, which shows that patient perceived convenience has a positive correlation with patient perceived value. In addition, there is no relationship between the degrees of time adequacy in medical treatment and patient perceived value, so that the hypothesis 3 is false. Moreover, the hypothesis 4 is partly true, which shows that patient characteristics can affect their perception of time extent and medical convenience.

There is no relevance between patient perceived medical convenience, patient perceived value and the time adequacy of medical treatment. On the whole, neither the perceived medical convenience nor patient perceived value is sensitive to patients' time adequacy. It would be caused by two reasons. For one thing, the medical service has its own particular nature. It closely relates to human life and health, so patients always pay more attention to the effect of medical treatment. They think that well-known hospitals have more advanced equipment of inspection and professional health care, so that the medical convenience has been paid less attention by patients. For another, it is related to the patients' expectations. Taizhou Hospital, one of the top hospitals in China, loads a large flow of patients and the doctors and staff have a heavy workload. Thus, the big hospitals' convenience extent for patients is less than that of small hospitals or community clinics. However, patients could predict the less convenience and would not over expect the convenience level in big hospitals. The phenomenon of blind choosing large hospitals is not beneficial to hospitals and would lead to waste of medical resources, which cannot improve the quality of medical care and finally might affect the patients perceived value. Therefore, it is suggested that medical institutions should guide patients to choose medical institutions rationally and reduce the blind behavior by various methods.

Inpatients have more advantage than outpatients in term of medical convenience. This result would be caused by the fact that outpatients' treatment process of is more complex than inpatients. They have to wait to register, to be examined and to pay fee step by step. Moreover, if it is the first time for a patient to see a doctor, unfamiliarity with a hospital's environment could trouble the patient more. As a result, outpatients have stronger feelings of waiting time and treatment process than that of inpatients. It also reflects that medical institutions should do more efforts to improve the service for outpatients, such as providing multi-access reservation, explicit signs and qualified guide service within a hospital.

Old patients are more satisfied with the medical convenience than young patients. The findings show that the group of patients over 50 years old has more satisfaction with the convenience of medical service while the "age 1829" group and "age 30-39" group present less satisfaction. It is because the older group has more tolerance for waiting time and is mostly accompanied by family members. Oppositely, younger patients have higher expectation of convenience because of their tight work schedule. Medical institutions may offer personalized service or increase available time to different patients, like providing regular emergency service and specialist clinic at weekends, etc. Additionally, principles of psychology can be applied into service to offer patients amusing service during waiting time to shorten patients' time perception, such as playing video in waiting rooms, free beverage and snacks, and reading materials.

\section{ACKNOWLEDGMENT}

This work was supported by the general program of national natural science foundation of zhejiang province of china [grant no.ly12g02008] and humanity and social science youth foundation of ministry of education of china[grant no.12yjc630154].

\section{REFERENCES}

[1] L. L. Berry, K. Seiders, and D. Grewal, "Understanding Service Convenience," Journal of Marketing, vol. 66(3), pp. 1-17, 2002. 
[2] M. M. Davis, and T. E. Vollman, "A Framework for Relating Waiting Time and Customer Satisfaction in a Service Operation," Journal of Services Marketing, vol. 4(1), pp. 61-69, 1990.

[3] M. G. Gallarza, and I. G. Saura, "Value dimensions perceived value, satisfaction and loyalty: an investigation of university students, travel behavior [J]," Tourism Management, vol. 27(3), pp. 437-452, 2006

[4] S. M. Keaveney, "Customer Switching Behavior in Service Industries: An Exploratory Study," Journal of Marketing, vol. 59(4), pp. 71-82, 1995.
[5] R. Kisang, H. Heesup, and T. H. Kim, "The relationships among overall quick-casual restaurant image, perceived value, customer satisfaction, and behavioral intentions [J]," International Journal of Hospitality Management, vol. 27(1), pp. 118-128, 2008.

[6] F. C. Pan, and C. S. Chen, "Enhancing Competitive Advantage of Hospitals through Linguistics Evaluation on Customer Perceived Value [J]," The Journal of American Academy of Business, vol. 9, pp. 481-485, 2004.

[7] V. A. Zeithaml, "Consumer perceptions of price, quality and value: a means-end model and synthesis of evidence $[\mathrm{J}]$," Journal of Marketing, vol. 52(3), pp. 2-22, 1988. 